\title{
The pragmatic marker you know in learner Englishes
}

\section{Lieven Buysse}

\author{
KU Leuven \\ Published in: Journal of Pragmatics 121, 40-57. \\ https://doi-org.kuleuven.ezproxy.kuleuven.be/10.1016/j.pragma.2017.09.010
}

\begin{abstract}
The present study investigates the pragmatic marker you know in native and learner English. Previous research on you know has suggested that it is highly frequent among native speakers but is used much less by non-native speakers, and that the latter do not use it intersubjectively but rather for discourse-organisational purposes. These claims are put to the test in a quantitative and qualitative analysis of four components of the Louvain International Database of Spoken English Interlanguage (LINDSEI), involving upperintermediate to advanced Dutch, French, German and Spanish learners of English. Comparisons are made with native discourse as it appears in LINDSEl's reference corpus LOCNEC. Nine functions are attested for you know in the corpus, and none of these are restricted to the native corpus. Native and non-native speakers alike use you know in highly intersubjective contexts. The main differences between speaker groups are found in the frequency of use: all learner groups use you know consistently less frequently than their native peers, and there are markedly fewer learners in each group who use you know at all.
\end{abstract}

\section{Keywords}

you know; learner English; pragmatic markers; EFL

\section{Introduction}

In the research on pragmatic markers you know has often been named as one of the most typical items that belong to this heterogeneous class of items. This status can probably be attributed to, on the one hand, some influential studies in the early stages of the research domain (most notably Östman 1981; Holmes 1986; Schiffrin 1987), and on the other hand its high frequency in native speaker discourse. One particular challenge has been to account for the versatility that you know shows, in that it may occur at the beginning, end or in the 
middle of a turn or clause, and has many "disparate functions" (Fox Tree and Schrock 2002: 736). Erman (2001) distinguishes three functional domains in which you know plays a role. As a textual monitor it organizes discourse and creates coherence, both at clause level (e.g. introducing a change of information content) and at the textual level (e.g. between a speaker's position and its backing). As a social monitor it sends conversation management signals such as indicating the willingness to yield a turn or make sure that the hearer has understood what has just been said. In the metalinguistic domain, finally, you know may indicate a lack of accuracy or emphasise the illocutionary force of an utterance.

Accounts of what a unified or basic meaning of you know might look like have distilled two significant elements, both of which highlight the marker's orientation towards the addressee. On the one hand, you know is viewed as a marker of common ground (e.g. Östman 1981; Stubbe and Holmes 1995; Jucker and Smith 1996; Beeching 2016), with which "[t]he speaker strives towards getting the addressee to cooperate and/or to accept the propositional content of his utterance as mutual background knowledge" (Östman 1981: 17). On the other hand, you know is an inferential marker which "invites the addressee to complete the argument by drawing the appropriate inferences" (Jucker and Smith 1998: 737), or in broader terms serves as "an invitation to infer the speaker's intentions" (Fox Tree and Schrock 2002: 743). When these two features are joined together, you know can be characterized as a marker that invites a co-participant to draw inferences about assumed common ground. This may entail an instruction to retrieve assumed background knowledge but just as well to establish or even question common ground.

In sharp contrast with other frequent pragmatic markers like well, you know has not attracted a great deal of attention in non-native discourse. This may be due to the observation that it is highly infrequent in learner English in those studies that do include you know. Romero Trillo (2002) finds, for example, that Spanish learners of English do not develop their pragmatic competence to the extent that they master the functions of interpersonal markers such as you know. Müller (2005) analyses you knowin English dyad conversations between native speakers of German, and compared these with similar native data. She found that all functions observed for the native speakers of American English also surfaced in the non-native corpus, but that on average the frequency of you know was five times lower in the non-native than in the native corpus.

In her investigation of you know in an English as a Lingua Franca (ELF) setting House (2009) concludes that (i) if a speaker uses you know they will use it with a high 
frequency, (ii) you know often co-occurs with connectors (because, and, but), in which case it acts as a "connection booster" (2009: 189), reinforcing the relation expressed by the connector, and (iii) you know is speaker-centred rather than addressee-centred as it is meant to monitor the speaker's progression in discourse. This, House (2009) points out, clearly diverges from native speaker practice, where you know has been demonstrated to be inherently intersubjective (i.e. you know is a signal of the speaker's attention to a coparticipant). Her tentative explanation for this finding is that "[i]t may well be the case (...) that ELF speakers as non-native speakers of English and as speakers who are not learners of English and do not aim at native competence are altogether too concerned with their own discourse production to be primarily 'intersubjectively' oriented” (House 2009: 189).

The present study takes its cue from this observation, and aims to establish whether the functions you know performs in a variety of learner Englishes can be likened to those in native English, and whether these are indeed intersubjective. In Section 2 the corpus and methodology will be introduced. Section 3 gives an overview of the results both in quantitative terms and in the form of an analysis of the functions you know fulfils in the corpus, which is further discussed in Section 4.

\section{Data and methodology}

For this study four components of the Louvain International Database of Spoken English Interlanguage (LINDSEI; Gilquin et al. 2010) were selected, viz. those with native speakers of Dutch, French, German and Spanish. The combination of different learner groups should (i) enable us to get a more comprehensive view of you know in learner discourse regardless of the learners' L1, and (ii) nonetheless facilitate the identification of features (if any) particular to learners with a specific L1 background. The LINDSEI components were selected on the basis of two criteria: the L1s of the learner groups could not be too divergent (hence two Romance and Germanic languages and not e.g. two Germanic languages, one Slavic and one East Asian language), and the researcher ought to be sufficiently familiar with the L1s.

All participants in LINDSEI were students of English in their second or third year at university, which means that they have almost reached the highest possible level of formal instruction in their respective countries. The data consist of interviews of about fifteen minutes each that were all conducted according to the same format: the interviewee first 
talked for one or two minutes about a topic such as a film, book, travel experience or a lifechanging experience, which sparked a conversation with the interviewer; at the end of each interview the students were asked to tell a short story based on four pictures. In total 200 interviews with non-native speakers, representing 321,809 tokens of learner speech, were analysed (Table 1). The non-native data were complemented with LINDSEl's native speaker reference corpus, the Louvain Corpus of Native English Conversation (LOCNEC), which followed the same format and involved 50 British interviewees who were university students in the Humanities.

\begin{tabular}{lccccc}
\hline & \multicolumn{2}{c}{ LINDSEI } & \multicolumn{2}{c}{ LOCNEC } \\
& Dutch & French & German & Spanish & \\
\hline interviews & 50 & 50 & 50 & 50 & 50 \\
total tokens & 92,865 & 134,844 & 105,955 & 80,467 & 170,533 \\
total tokens interviewee turns & 79,652 & 91,402 & 85,951 & 64,804 & 125,666 \\
average tokens interviewees & 1,492 & 1,666 & 1,624 & 1,242 & 2,513 \\
\hline
\end{tabular}

All tokens of you know (including those transcribed as $y^{\prime} k n o w$ ) were identified in a collocation search in Wordsmith Tools 5.0. Those instances that can be analysed as consisting of a combination of the subject and predicator of a clause, as in (1), were subsequently discarded as non-pragmatic marker occurrences of the collocation pattern.

(1) $<$ B > don't you know that I have the power to either crucify you or set you free $</ B>$ $(\mathrm{GE3} 1)^{1}$

For each pragmatic marker token of you know the function it performs in the discourse was then determined. This resulted in a set of nine functions (Table 2). As will become clear in Section 3.2, many of these functions have also been attested in prior research albeit often described differently. In order to facilitate the categorisation process the functional assessment of each token was complemented with an assessment of certain

\footnotetext{
1 The transcription conventions for LINDSEI have been included in the Appendix. Each example is followed by the identification number of the interviewee, in which the letters refer to the interviewee's L1: DU is Dutch, FR is French, GE is German, SP is Spanish, and NS is 'native speaker'.
} 
formal features. For example, for the first function (introduce a proposition) you know always occurs in interclausal position, whereas for the second function (elaborate a preceding concept) it relates a proposition to a preceding word or phrase but not a clause, and for the third function (highlight particular points in the discourse) you know always occurs in intraclausal position.

Table 2 Pragmatic marker functions of you know

\begin{tabular}{ll}
\hline Function & Abbrev. \\
\hline $\begin{array}{l}\text { Introduce a proposition linked to the prior discourse as one the co- } \\
\quad \text { participant is expected to relate to }\end{array}$ & PROP \\
Elaboration of a preceding concept & ELAB \\
Highlight particular points in the discourse & HIGH \\
Editing marker & EDIT \\
Explicit invitation to make inferences & INF \\
Mark an approximative formulation & APPR \\
Comprehension-securing you know & COMP \\
Transition to reported speech & QUOTE \\
Indicate a transition-relevance place & TRP \\
\hline
\end{tabular}

The robustness of the classification was tested by having a second rater classify each token independently after he had been introduced to the discriminating features of each functional category. This yielded a correspondence rate of $97.3 \%$, with only 32 tokens that required further tuning between raters.

Some tokens of you know could not be classified in a functional category because a part of the adjacent co-text was unintelligible, making it impossible to interpret the function of you know, as shown in excerpt (2). This was the case for 18 tokens (1.54\% of all tokens of you know analysed): 4 in the French learner corpus, 3 in the Spanish, and 11 in LOCNEC.

(2) $<$ B $>$ so it's a crafty machine $</ B>$

$<$ A $>$ yeah I know $<$ laughs $></ A>$

$<B>$ it's very well worked out you know $\langle X X></ B>$

(NS11) 
In a quantitative analysis all tokens of you know were counted, along with their functional categories, within each sub-corpus. Observed differences in frequency between the sub-corpora were tested by performing an independent-samples Kruskal-Wallis test, which was corrected for tied ranks, on the absolute frequencies in the statistical software programme SPSS 23. If statistically significant differences were detected within the population, SPSS automatically selected post-hoc tests for a pairwise comparison of the sub-corpora.

\section{Results}

\subsection{Frequency of use}

In total 1,169 tokens of you know were attested with a pragmatic marker function in the corpus. There is a clear divide in the frequency of you know in the learner sub-corpora and that in the native corpus (Table 3).

Table 3 Overview for each sub-corpus of you know in absolute $(\mathrm{N})$ and relative (rel.) frequencies (per 10,000 words of interviewee speech), number of interviewees using you know (N int.), the range of absolute frequencies for those interviewees using you know, and averages in terms of the total number of interviewees using you know and of the total number of interviewees in the sub-corpus

\begin{tabular}{lrrrrrc}
\hline & N & rel. & N int. & range & av./N int. & av./total N int. \\
\hline LINDSEI-DU & 183 & 22.97 & 21 & $1>54$ & 8.71 & 3.66 \\
LINDSEI-FR & 176 & 19.26 & 28 & $1>46$ & 6.29 & 3.52 \\
LINDSEI-GE & 71 & 8.26 & 17 & $1>24$ & 4.18 & 1.42 \\
LINDSEI-SP & 166 & 25.62 & 29 & $1>41$ & 5.72 & 3.32 \\
\hline LOCNEC & 573 & 45.60 & 45 & $1>60$ & 12.73 & 11.46 \\
\hline
\end{tabular}

All learner groups use you know considerably less often than the native speakers. All but five participants in LOCNEC employ you know at least once, compared with between 17 and 29 learners. The Dutch, French and Spanish sub-corpora are situated in the same frequency band (19-25 tokens per 10,000 words), and have a similar number of interviewees using you know (21-29). The German sub-corpus scores considerably lower, with a relative frequency smaller than one third of that of the French sub-corpus and smaller than one fifth of the native sub-corpus. 
The independent-samples Kruskal-Wallis test was highly significant: $X^{2}(4, N=250)=$ $55.44, p=.000$. The post-hoc tests indicate that statistically significant differences hold at $p$ $<.001$ between LOCNEC and all learner sub-corpora (for DU $\mathrm{H}=80.90$, for $\mathrm{FR} \mathrm{H}=67.98$, for GE H=93.95, for SP H=66.47), but no significant differences can be established between any of the learner sub-corpora.

Fewer than half of the German interviewees use you know at least once, and the highest absolute incidence in a single interview is only 24 tokens (compared with over 40 in each of the other learner groups). Figure 1 indicates that an overwhelming majority of learners only use you know between 1 and 9 times in an interview (71\% in DU, 83\% in SP, $86 \%$ in $\mathrm{FR}$ and even $94 \%$ in GE), whereas just under half of their native peers are in the same range. It would, therefore, appear that House's (2009) observation for ELF discourse that speakers use you know either consistently or not at all does not apply to the learner data in the present study.

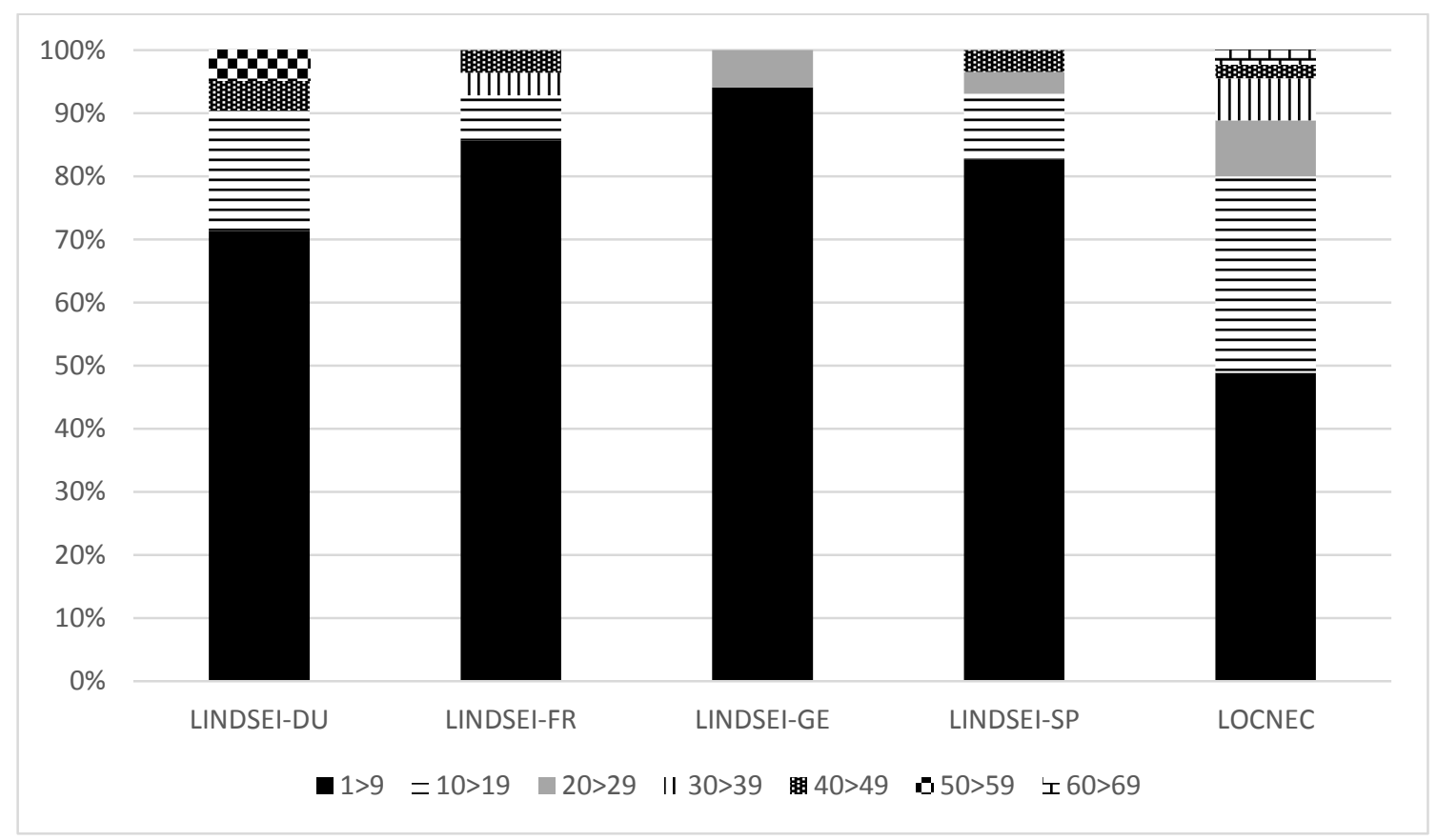

Figure 1 Share of interviewees in the distribution range of you know in each sub-corpus

3.2 Functional analysis

3.2.1 Introduce a proposition linked to the prior discourse as one the co-participant is expected to relate to 
You know can introduce a proposition which is (i) a claim, (ii) an event or state in narrative discourse, (iii) an argument to a prior claim, or (iv) background information. In each of these cases the upcoming proposition directly follows on from the prior co-text and you know marks it as one the co-participant should be able to relate to.

When you know introduces a claim (cf. Erman, 2001: 1342; Fox Tree and Schrock, 2002: 740), it does not mark that the upcoming utterance is part of the common ground between the speaker and a co-participant, but rather seeks to expand common ground between them by signaling that the speaker finds the upcoming utterance logical so the coparticipant can relate to it. In excerpt (3) the interviewee responds to the question whether she would like to go into teaching after graduating from university in a few years' time. The initial response is negative but the interviewee would still consider taking a teacher training course ("aggregation"). The uncertainty voiced in the first clauses of this example leads to the claim that the interviewee may even decide that, rather than looking for a job, she will want to continue studying. The co-participant can infer that this claim is logical given the relatively long period between the interview and graduation (one and a half years), in which anything could happen. Similarly, in (4) the interviewee is discussing his plans for the future as well. He is asked whether his degree in Italian is meant to lead to a teaching career. Here too uncertainty abounds with ultimately the conclusion that he might not teach Italian in England but rather English in Italy. Again this is presented as a logical claim, in this case based on the prior discourse: if you put two and two together, this might be an option. Note that in both cases the nature of the relation between the upcoming proposition and the prior co-text is highlighted by a pragmatic marker with a connective function (contrastive but and conclusive so, respectively). So you know does not express this relation itself but rather draws the interviewers' attention to issues of common ground and intersubjectivity.

(3) $<$ B > teacher no I don't really like teaching (er) I don't know maybe I would do (er) you know extra year $<X>$ year to: to get the aggregation but (erm) . I don't know I don't know I still don't know right now I wouldn't do it . but you know within (er) one year and a half when I will (eh) look back and say . oh God my university life is over and maybe I will . you know want to .. to continue I mean </B> (FR40) 
(4) <A> so you . would you like to study well to: to teach . Italian after <overlap /> you've finished or is it just to: $</ A>$

$<$ B $><$ overlap $/>$ erm .. I don't know well possibly I w= you know I'm not too sure what I'm gonna do at the end of= the degree's .. open ended but . I mean I'm doing a few courses in linguistics all about sort of language teaching $</ B>$ $<\mathrm{A}>\mathrm{mhm}</ \mathrm{A}>$

$<B>$ so: you know perhaps I'm looking towards teaching English . in Italy perhaps $</ \mathrm{B}>$

(NS14)

You know may also preface a proposition that refers to a state or event in a narrative (cf. Schiffrin, 1987: 281-284; Erman, 2001: 1342-1344; Fox Tree and Schrock, 2002: 740; González, 2004: 187-188; Müller, 2005: 171-175), in which case it signals that the coparticipant should find the scene called up in the utterance familiar for anyone acquainted with a context like the one sketched by the speaker ('you know how it goes'). In (5), for example, the interviewee recounts his spur of the moment decision to go on a distant trip, whereas in (6) the interviewee explains that he wandered round the area of Saint Mark's Square in Venice, as one does around iconic squares.

(5) $\quad<B>(\ldots)$ and then I just. one day I just went to the travel agency with my dad and I booked my ticket $</ B>$

$<\mathrm{A}>(\mathrm{mhm})</ \mathrm{A}>$

$<B>$ and all of a sudden I was gone you know I was just standing on the airport at six o'clock in the morning and I was . ready to go with my backpack $(\ldots)</ B>$ (DU27)

(6) $<B>$ no . but we went to Saint Mark's square and $</ B>$ $<\mathrm{A}>\mathrm{mhm}</ \mathrm{A}>$

$<B>$ you know wandered round a bit $<$ /B $>$ (NS10)

In prefacing an argument (cf. Schiffrin, 1987: 279-281; Erman, 2001: 1342-1343; Fox Tree and Schrock, 2002: 740) the speaker also marks the upcoming proposition as one a co-participant is able to relate to by drawing on their knowledge of the world. In example (7) 
the interviewee talks about going to a summer camp with HIV infected children that has just been mentioned, and adds that this will only last a week. The reason for this restricted period is prefaced by you know. such children get tired easily, which can readily be understood from the earlier explanation of the children's situation. In (8) the interviewee puts recent water shortages in England down to bad management because drier parts of Europe experience fewer problems than England does. The co-participant is expected to award this argument a place in her framework of reference.

(7) $\quad<A>$ and what are your future plans .. this summer $</ A>$

$<$ B $>$ we are going $</ B>$

$<A>$ to the camp $</ A>$

$<B>$ yeah . yeah just one week because $</ B>$

$<$ A $>$ okay $</ A>$

$<B>$ you know they get really tired and . they they miss their homes but $</ B>$ $<$ A $>$ okay $</ A>$

$<$ B $>$ it's enough $</ B>$

(SP17)

(8) $\quad<$ A $><$ laughs $>$ because er . I think a bit everywhere they have problems with the water supplies $</ A>$

$<$ B $>$ yeah: . yeah allegedly yeah $</ B>$

$<$ A $>$ allegedly why $</ A>$

$<B>$ well $<X X X>$ water problems is bad management you know lots of places have

lots less water than we do and have no problems the Canaries for example

$<$ begin_laughter $></ B>$

(NS25)

Finally, a proposition can also be introduced by you know when it parenthetically adds background information (cf. Schiffrin, 1987: 274; Erman, 2001: 1344; Fox Tree and Schrock, 2002: 740; Müller, 2005: 186; Redeker, 2006: 345) that is necessary either to fully comprehend the story or argumentation or to put into perspective what has just been said. The former is illustrated in (9), where the interviewee describes a hunting experience in Australia and introduces mid-story that she was in the back of the vehicle so the interviewer can better picture the situation. In (10), on the other hand, the interviewee tells about a trip to 
the Canadian Arctic where the food was not appreciated by the travellers, as a result of which they lost weight. The interviewee adds that she was already fairly thin before the trip, which helps the interviewer to picture what the statement "we all lost weight" means from the interviewee's perspective.

(9) $<B>(\ldots)$ and they they go with this huge flash flash light and the guns and (er) $<$ swallows $>$ you know I was in the back of the ute . and (er) they just sort of . shine with the flash light and if they see kangaroos they just shoot them . and after <laughs> two kangaroos I started crying and I wanted to go home $(\ldots)<$ /B> (DU27)

(10) $<$ A $>$ I suppose you lost weight or $<$ laughs $></ A>$ $<B>$ yeah we all lost weight you know I'm I was quite thin to start with so I did not lose too much but. some people lost two or three stone $</ B>$ (NS55)

In the native sub-corpus over one quarter of all tokens of you know introduce a proposition as a claim, state or event, argument or parenthetical information (Table 4). Similar shares can be found in the non-native sub-corpora, but the relative frequencies are considerably lower as these are about half as high in the Dutch and Spanish sub-corpora as in LOCNEC, and even lower for the French and German sub-corpora. The latter is quite remarkable: with the lowest relative frequency of all sub-corpora it accounts for over one third of all tokens of you know in the German sub-corpus.

Table 4 Quantitative overview of the function 'Introduce a proposition' of you know

\begin{tabular}{lrrrr}
\hline & N & \multicolumn{1}{c}{ Rel. } & Share & N int. \\
\hline LINDSEI-DU & 54 & 6.78 & 29.19 & 11 \\
LINDSEI-FR & 45 & 4.92 & 25.57 & 14 \\
LINDSEI-GE & 25 & 2.91 & 35.21 & 8 \\
LINDSEI-SP & 40 & 6.17 & 24.10 & 14 \\
\hline LOCNEC & 156 & 12.41 & 27.23 & 33 \\
\hline
\end{tabular}

The independent-samples Kruskal-Wallis test was highly significant: $X^{2}(4, N=250)=$ $39.90, p=.000$. The post-hoc tests indicate that statistically significant differences hold at $p$ 
$<.001$ between LOCNEC and all learner sub-corpora (for DU H=59.52, for FR H=54.46, for GE $\mathrm{H}=67.36$, for $\mathrm{SP} \mathrm{H}=55.01$ ), but no significant differences can be established between any of the learner sub-corpora.

These numbers can be further broken down for each of the sub-functions. Figure 2 shows the share of these sub-functions in the overall incidence within each sub-corpus of this category, and the data table below the graph provides the corresponding relative frequencies ( $\mathrm{N}$ tokens per 10,000 words). Given the relatively low frequencies differences in these shares may be due to fluctuations in the need to express specific relations; if, for example, there are more argumentative passages in an interview, there is likely to be a greater need to introduce propositions.

Figure 2 Share of each sub-function within the category 'Introduce a proposition' for each subcorpus (graph), and relative frequencies (data table)

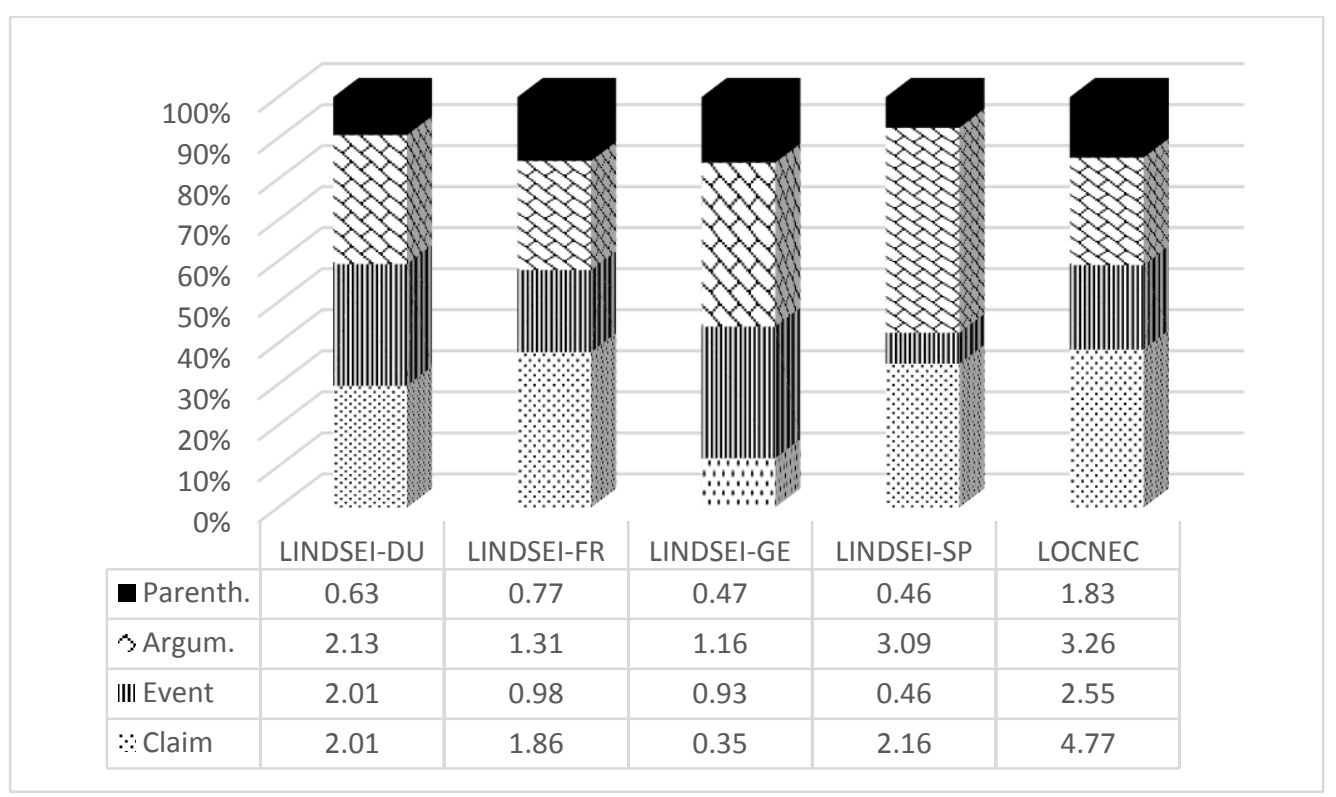

Interestingly, in this category you know frequently collocates with connectives. This is not very surprising since you know here occurs in between two clauses. Since these clauses are propositionally related, speakers may feel that some form of connective marking is necessary, and you know itself does not have this type of connective potential. Table 5 lists these connectives for the five sub-corpora. What is most striking is that the non-native speakers combine you know more often with a connective than the native speakers: for the Dutch, French and Spanish learners this is the case for over 7 out of 10 tokens of you know 
in this category $(70.37 \%, 71.11 \%$ and $72.50 \%$, respectively), for the German learners in over half of cases $(52.00 \%)$, but for the native speakers only in over one third of cases $(35.90 \%)$.

Table 5 List of collocations with connectives for the category 'Introduce a proposition' with absolute and relative (per 10,000 words) frequencies

\begin{tabular}{lcccccccccc}
\hline & \multicolumn{3}{c}{ LINDSEI-DU } & \multicolumn{2}{c}{ LINDSEI-FR } & \multicolumn{3}{c}{ LINDSEI-GE } & \multicolumn{3}{c}{ LINDSEI-SP } & \multicolumn{2}{c}{ LOCNEC } \\
& $\mathrm{N}$ & rel. & $\mathrm{N}$ & rel. & $\mathrm{N}$ & rel. & $\mathrm{N}$ & rel. & $\mathrm{N}$ & rel. \\
\hline and & 13 & 1.63 & 6 & 0.66 & 3 & 0.35 & 7 & 1.08 & 24 & 1.91 \\
and now & 0 & 0.00 & 1 & 0.11 & 0 & 0.00 & 0 & 0.00 & 0 & 0.00 \\
and then & 3 & 0.38 & 1 & 0.11 & 1 & 0.12 & 0 & 0.00 & 0 & 0.00 \\
because & 7 & 0.88 & 8 & 0.88 & 8 & 0.93 & 15 & 2.32 & 10 & 0.80 \\
but & 12 & 1.51 & 9 & 0.98 & 0 & 0.00 & 7 & 1.08 & 9 & 0.72 \\
now & 0 & 0.00 & 1 & 0.11 & 0 & 0.00 & 0 & 0.00 & 0 & 0.00 \\
so & 3 & 0.38 & 6 & 0.66 & 1 & 0.12 & 0 & 0.00 & 13 & 1.03 \\
\hline Total & 38 & 4.78 & 32 & 3.50 & 13 & 1.52 & 29 & 4.48 & 56 & 4.46 \\
\hline
\end{tabular}

This might point at a stronger desire among the learners to make coherence relations explicit. Indeed, a quick search of the corpus for the overall incidence of the conjunctions that co-occur most frequently with you know-and, but and because-indicates that, on the whole, these markers are more common in the learners' discourse than in the native speakers'. In Table 6 the relative frequencies that are higher in the learner corpora have been highlighted.

Table 6 Absolute and relative (per 10,000 words) frequencies of and, but and because in each sub-corpus

\begin{tabular}{lcccccccccc}
\hline & \multicolumn{2}{c}{ LINDSEI-DU } & \multicolumn{2}{c}{ LINDSEI-FR } & \multicolumn{2}{c}{ LINDSEI-GE } & \multicolumn{2}{c}{ LINDSEI-SP } & \multicolumn{2}{c}{ LOCNEC } \\
& $\mathbf{N}$ & rel. & $\mathbf{N}$ & rel. & $\mathbf{N}$ & rel. & $\mathbf{N}$ & rel. & $\mathbf{N}$ & rel. \\
\hline and & 3,424 & 429.9 & 3,533 & 386.5 & 3,610 & 420.0 & 2,721 & 419.9 & 4,666 & 371.3 \\
but & 1,131 & 142.0 & 1,241 & 135.8 & 896 & 104.3 & 800 & 123.5 & 1,359 & 108.1 \\
because & 676 & 84.9 & 670 & 73.3 & 667 & 77.6 & 672 & 103.7 & 833 & 66.3 \\
\hline
\end{tabular}

3.2.2 Elaboration of a preceding concept 
Instead of occurring in between two full-fledged clauses you know can also signal that a concept - often consisting of nothing more than a word or phrase - that occurred within the prior utterance is about to be modified. The elaboration can take the form of a clarification (as in (11) and (12)), a paraphrase (as in (13) and (14)) or of an example (as in (15) and (16)). All of these are strategies aimed at overcoming potential inaccuracies in the prior discourse to prevent misunderstanding. Similar functions have been described by Erman (2001) as introducing a change of information content and modifying previous discourse, by Fox Tree and Schrock (2002) as clarifying a prior utterance, and by Müller (2005) as introducing an explanation.

(11) $<B>(\ldots)$ it's a a bit frustrating when I go to: (er) cap= (er) capitals because I think it's real= sort of oppressing $<$ overlap $/>$ you you know a lot of people $</ B>$ $<$ A $><$ overlap $/>$ yeah I know what you mean $</ A>$ $<B>$ (er) shouting and all the noise. and the the cars $<$ overlap $\mid></ B>$ (FR07)

(12) $<B>\cos$ in the in the[i:] original edition of the book had a like a a glossary in the back you know like er this means this means that $</ B>$ (NS53)

(13) $<B>$ but the others . you know the smallest ones . they . they can't understand it $</ \mathrm{B}>$ (SP17)

(14) $<B>$ erm but er it it was obviously because . you know it it was felt within sort of the powers that be you know . the American high command </B> $<\mathrm{A}>\mathrm{mhm}</ \mathrm{A}>$ $<B>$ it must have been felt that something like this could have happened and then somebody'd obviously felt well let's let's do a film about it while it's still valid $</ B>$ (NS27)

(15) $<B>(\ldots)$ cos it was difficult to come up with a . superlative in a way you know the

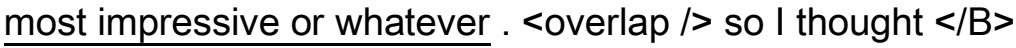
(GE22) 
(16) $<$ B > and it's it's not sort of .. big screen names . you know it's not Tom Cruise or Brad Pitt $</ B>$

(NS15)

Relatively few learners use you know to clarify, paraphrase or illustrate a preceding concept, which is also reflected in relative frequencies that do not amount to more than half of the native frequency (Table 7). Interestingly, the French and Spanish learners make greater use of you know to this effect than their Dutch and German peers.

The independent-samples Kruskal-Wallis test was highly significant: $X^{2}(4, N=250)=$ 43.11, $p=.000$. The post-hoc tests indicate that statistically significant differences hold at $p$ $<.001$ between LOCNEC and all learner sub-corpora (for $\mathrm{DU} H=54.67$, for $\mathrm{FR} \mathrm{H}=44.81$, for GE $\mathrm{H}=63.66$, for $\mathrm{SP} \mathrm{H}=53.21$ ), but no significant differences can be established between any of the learner sub-corpora.

Table 7 Quantitative overview of the function "Elaborate a preceding

concept' of you know

\begin{tabular}{lrrrr}
\hline & N & Rel. & Share & N int. \\
\hline LINDSEI-DU & 10 & 1.26 & 5.41 & 8 \\
LINDSEI-FR & 19 & 2.08 & 10.80 & 12 \\
LINDSEI-GE & 7 & 0.81 & 9.86 & 4 \\
LINDSEI-SP & 19 & 2.93 & 11.45 & 8 \\
\hline LOCNEC & 75 & 5.97 & 13.09 & 28 \\
\hline
\end{tabular}

\subsubsection{Highlight particular points in the discourse}

As Erman (2001) points out, at clause level you know can be used "to mark certain elements in the thematic structure" (2001: 1342). Typically this means that you know does not introduce an entire main clause but rather highlights a particular element within a clause. This may be a 'given' element, which therefore belongs to the co-participants' common ground, as in (17) where "in a very aggressive way" refers back to the interviewee's dislike of aggressiveness, and in (18) where the interviewee had just mentioned that the film The Remains of the Day is in part about how a Lord deals with two Jewish refugees. In both cases the interviewee may also have counted on the interviewer's knowledge of the context 
referred to: in the former the interviewer can be expected to be familiar with Belgian (or Western) attitudes, and in the latter with the perilous position of Jews in the Second World War.

(17) $<$ B $><$ laughs $>$ yeah but that's true they're . they're not aggressive and that's the important thing I don't like (er) aggressivity as you have it in here in Belgium and you can't .. (eh) w= when you just when you're just walking on street and (er) if you if you meet someone. there's a good chance if . you . come too close to him that he will look at you you know in a very aggressive way . which is very very unpleasant well I mean it's . it's not very important </B $>$ (FR21)

(18) $<B>$ and one of the major . points is that these two Jewish girls who get taken on as refugees $</ B>$

$<\mathrm{A}>\mathrm{mhm}</ \mathrm{A}>$

$<B>$ half way through the film he has an argument with the housekeeper Emma Thompson that they be kept he .. said it's the the Lord's wishes they've got to go . erm and the the Lord's only justification was that you know they were Jewish $</ B>$ $<\mathrm{A}>\mathrm{mhm}</ \mathrm{A}>$ $<$ B $>$ because he was German $</ B>$ (NS21)

Alternatively, elements may receive focus because they are prefaced with you know although they have not appeared in the prior co-text but for which the interviewee merely appeals to the interviewer's knowledge of the world and empathic capacity. In (19) and (20) the interviewees draw attention to what they are like and what impressed them about a country, respectively.

(19) $<B>$ (erm) I guess so yeah. at least. other people say I am but sometimes I'm you know quiet to the outside but inside I'm: like a like a volcano <laughs> sometime $</ B>$ (GE02)

(20) $<B>(.$.$) and I was just really impressed you know with the way things ran and .. it$ was just really good I really liked it $</ B>$ 
(NS49)

In each of the learner sub-corpora only 7 learners made use of this function of you know, which contrasts sharply with the native speakers (27 interviewees). Although the relative frequencies in the learner sub-corpora do not amount to more than half of that in LOCNEC, for the Dutch, German and Spanish groups this function takes up shares that are comparable to that for the native group.

The independent-samples Kruskal-Wallis test was highly significant: $X^{2}(4, N=250)=$ 43.29, $p=.000$. The post-hoc tests indicate that statistically significant differences hold at $p$ $<.001$ between LOCNEC and all learner sub-corpora (for $\mathrm{DU} H=54.61$, for $F R H=55.49$, for GE $\mathrm{H}=55.40$, for $\mathrm{SP} \mathrm{H}=53.85$ ), but no significant differences can be established between any of the learner sub-corpora.

Table 8 Quantitative overview of the emphasizing function of you know

\begin{tabular}{lrrrr}
\hline & N & \multicolumn{1}{c}{ Rel. } & Share & N int. \\
\hline LINDSEI-DU & 29 & 3.64 & 15.68 & 7 \\
LINDSEI-FR & 16 & 1.75 & 9.09 & 7 \\
LINDSEI-GE & 11 & 1.28 & 15.49 & 7 \\
LINDSEI-SP & 20 & 3.09 & 12.05 & 7 \\
\hline LOCNEC & 82 & 6.53 & 14.31 & 28 \\
\hline
\end{tabular}

\subsubsection{Editing marker}

Probably one of the most widely recognized functions of you know is that of an editing marker, occurring at moments where a speaker is looking for the right word or content, or needs to repair a prior utterance. As such it "encourage[s] addressees to infer the intentions" (Fox Tree and Schrock, 2002: 738) when speakers have difficulties expressing themselves. In (21) and (22) the interviewee is looking for the appropriate phrase, which is in the former highlighted by hesitation through the repetition of the particle to and the pauses preceding and following you know, and in the latter by the multiple repetition of the article the. 
(21) $<B>(\ldots)$ and (er) actually th= the year we went in China was the year of . the: the property I mean (er) government tried to . you know . to: to make something about (er) this (er) filthy towns and (eh) street and so on (...)</B> (FR40)

(22) $<B>$ erm I found that the you know the the use of er of that costume and that setting was er . was really interesting $</ B>$ (NS47)

Editing can also involve restarts and reformulations. In excerpt (23) you know is used twice to this effect: first the interviewee retakes part of the clause (which is probably due to a search for the appropriate word or content), and then marks self-repair with the second you know. Also in (24) you know indicates self-repair through a restart.

(23) $<B>(\ldots)$ when I was working there for a year . I just . went there and I had an interview and . just next . you know next day I know that he . you know that I pass my interview and next day I started to work </B> (SP14)

(24) <B> erm it it did not do as well as it should have done because it did not you know there was not any violence there was not $\langle/ B>$ (NS15)

Learners sometimes explicitly indicate that they are looking for the right word, as in (25):

(25) $<B>$ so she also interprets for just (er) . the (er) justice (er) the dep= you know the what's it called the ministry of justice and (er) (er) and she gives classes to (er) adult education every Wednesday $(\ldots)</ \mathrm{B}>$ (DU36)

The editing function makes up the largest category in each of the learner subcorpora, ranging between over one fifth of tokens of you know in the German sub-corpus and about one quarter in the Dutch and French sub-corpora to one third in the Spanish subcorpus. Quite remarkably, a relatively high number of Spanish interviewees use the editing 
marker you know, and the relative frequency in this sub-corpus is almost identical to that in the native sub-corpus.

The independent-samples Kruskal-Wallis test was highly significant: $X^{2}(4, N=250)=$ 39.92, $p=.000$. The post-hoc tests indicate that statistically significant differences hold at $p$ $<.001$ between LOCNEC and LINDSEI-DU $(\mathrm{H}=58.70)$, LINDSEI-FR $(\mathrm{H}=58.02)$, and LINDSEI-GE $(\mathrm{H}=67.04)$, and at $p<.05$ between LOCNEC and LINDSEI-SP2 $(\mathrm{H}=37.83)$. No significant differences can be established between any of the learner sub-corpora.

Table 9 Quantitative overview of the editing function of you know

\begin{tabular}{lrrrr}
\hline & N & Rel. & Share & N int. \\
\hline LINDSEI-DU & 46 & 5.78 & 24.86 & 10 \\
LINDSEI-FR & 49 & 5.36 & 27.84 & 11 \\
LINDSEI-GE & 16 & 1.86 & 22.54 & 8 \\
LINDSEI-SP & 55 & 8.49 & 33.13 & 20 \\
\hline LOCNEC & 109 & 8.67 & 19.02 & 34 \\
\hline
\end{tabular}

\subsubsection{Explicit invitation to make inferences}

In clause-final position you know can explicitly invite co-participants to infer the full implication of the prior segment as "a self-evident fact" (Beeching, 2016: 102) given the context. In (26), for example, the interviewee considers it evident that a suggestion about the nature of the relationship between two characters in a film does not hold water because "that would be incest". Similarly, in (27) the interviewee contrasts a beach holiday to a city trip to Toronto, and makes the general statement that in the former case you only spend money on food.

\footnotetext{
2 The discrepancy between the observation that the relative frequencies of the Spanish learner corpus and LOCNEC are almost identical and the fact that this should nevertheless amount to a statistically significant difference can be explained by the way in which statistical tests are performed: these can only be based on absolute frequencies, as a result of which differences in corpus sizes are often neglected. Tests that do take corpus size into account have the disadvantage of neglecting other important characteristics such as the fact that each sub-corpus consists of data from 50 individual participants.
} 
(26) $<$ B > no (eh) . I I think that (em) .. a a good ending would be (eh) .. you know they they . fell in love each other because (eh) he is completely in love with her . and that's another another .. (eh) key thing that (eh) . because I (eh) . well I don't think that she . can be (eh) . his . daughter $</ B>$

$<$ A $><$ overlap $/>(\mathrm{mhm})</ \mathrm{A}>$

$<$ B $><$ overlap / $>$ because. (eh) that would be incest you know $<$ laughs $><$ B $>$ (SP18)

(27) $<B>$ which was a lot and then being there for two weeks and it was not normally I go on like say a beach holiday $</ B>$

$<A>$ uhu $</ A>$

$<B>$ and you just sit on the beach $</ B>$

$<$ A $><$ / overlap $>$ yes .. mhm $</ A>$

$<\mathrm{B}><$ / overlap $>$ you're not spending any money apart from on your food you know $</ \mathrm{B}>$

$<\mathrm{A}>\mathrm{mhm}</ \mathrm{A}>$

$<B>$ but there like some of the places it was like thirty pounds just to get it $<$ /B $>$ (NS49)

In the present corpus no evidence was found of Beeching's (2016) characterization of you know being used "slightly patronizingly" (2016: 102) because the statement is so evident "that no argument can be raised against it and that the addressee is rather stupid if they do not recognize this self-evident truth" (2016: 103). The explicitly inferential function of you know would, on the contrary, appear to foster the relationship between the interlocutors in this corpus, as the speaker involves co-participants by inciting them to actively engage in the thought process. Contrary to what Beeching (2016) describes, the statements involved need not be universal truths, but could just as well pertain to specific situations that co-participants are expected to be able to relate to. In (28), for example, the interviewee claims that his experience in Scotland - a group of guys without a chance of meeting any girls - is "not how it's supposed to be", and in (29) the interviewee conveys her highly personal emotions about visiting Disneyland.

(28) $<B>(.$.$) we were there . f=$ four guys . five days and .. we hadn't seen one .. one girl . and <laughs> . so to say . it was a bit too. we got really frustrated so 
<laughs>. it's not how it's supposed to be you know . we went to New York a one time one week and (er) . pff. we went out every day until six o'clock in the morning and . that's . the complete . the opposite of what we did in Scotland $(\ldots)</ B>$ (DU08)

(29) $<B>$ that was something l'd always wanted to do since l've been about five $</ B>$ $<\mathrm{A}>\mathrm{mhm}</ \mathrm{A}>$

$<B>$ so when I was there I couldn't believe I was there you know $</ B>$ (NS17)

The inferential function of you know is used by just under half of the native speakers, whereas between 6 and 10 learners in each non-native sub-corpus do so (Table 10). In the Dutch group this function takes up about the same share as in the native group $(15.14 \%$ and $14.31 \%$, respectively) but the relative frequency in the former is still considerably lower (3.52 versus 6.53 tokens per 10,000 words) as is the number of interviewees using it.

The independent-samples Kruskal-Wallis test was highly significant: $X^{2}(4, N=250)=$ 29.43, $p=.000$. The post-hoc tests indicate that statistically significant differences hold at $p$ $<.001$ between LOCNEC and LINDSEI-DU $(\mathrm{H}=44.85)$, LINDSEI-FR $(\mathrm{H}=43.45)$, and LINDSEI-GE $(\mathrm{H}=49.15)$, and at $p<.01$ between LOCNEC and LINDSEI-SP $(\mathrm{H}=39.45)$. No significant differences can be established between any of the learner sub-corpora.

Table 10 Quantitative overview of the inferential function of you know

\begin{tabular}{lrrrr}
\hline & N & Rel. & Share & N int. \\
\hline LINDSEI-DU & 28 & 3.52 & 15.14 & 7 \\
LINDSEI-FR & 13 & 1.42 & 7.39 & 8 \\
LINDSEI-GE & 7 & 0.81 & 9.86 & 6 \\
LINDSEI-SP & 13 & 2.01 & 7.83 & 10 \\
\hline LOCNEC & 86 & 6.53 & 14.31 & 24 \\
\hline
\end{tabular}

\subsubsection{Mark an approximative formulation}

Speakers can use you know when they feel that a word or phrase is not used with the greatest possible precision (Stubbe and Holmes, 1995: 69; Müller, 2005: 162). In such cases 
this lack of precision also tends to be signaled by an additional marker, such as the general extenders and all that stuffand or something in (30) and (31), respectively.

(30) $<$ B > and it's . good in the way that . you only have to study . and not <starts laughing> worry about <stops laughing > you know works and all that stuff $(\ldots)$ $</ B>$

(31) $<B>$ what what can you see is wrong and what can you see that you know and then if they do miss anything you can always say oh well have you noticed that the plugs have got you know five plugs in one socket or something $</ B>$ (NS19)

This category is negligible in quantitative terms (Table 11), with shares not rising above $5 \%$ and only a few interviewees making use of this function in each sub-corpus. The independent-samples Kruskal-Wallis test was not significant: $\mathrm{X}^{2}(4, N=250)=7.96, p=$ .093 .

Table 11 Quantitative overview of the approximation function of you know

\begin{tabular}{lrrrr}
\hline & N & \multicolumn{1}{c}{ Rel. } & Share & N int. \\
\hline LINDSEI-DU & 6 & 0.75 & 3.24 & 3 \\
LINDSEI-FR & 8 & 0.88 & 4.55 & 6 \\
LINDSEI-GE & 3 & 0.35 & 4.23 & 3 \\
LINDSEI-SP & 3 & 0.46 & 1.81 & 2 \\
\hline LOCNEC & 13 & 1.03 & 2.27 & 9 \\
\hline
\end{tabular}

\subsubsection{Comprehension-securing you know}

One of the functions closest to the ideational meaning of you know is when it seeks confirmation from a co-participant that they have understood what has just been said. This may pertain to either the level of content or of form. As such it reflects the speaker's uncertainty as to either the existence of common ground between the co-participants (content), or the accuracy and clarity of the speaker's words (form). Similar to the inferential 
function (see 3.2.5), you know here occurs in final position, because it overtly seeks involvement of a co-participant.

(32) $<B>(\ldots)$ because I I have been in Belfast in Ireland </B $>$

$<\mathrm{A}>$ oh $</ \mathrm{A}>$

$<$ B $>$ with a $<$ overlap $/>$ Erasmus $</ B>$

$<$ A $><$ overlap $/>$ beautiful $</ A>$

$<$ B $><$ overlap $/>$ yes $</$ B $>$

$<$ A $><$ overlap / I've never been there $</ A>$

$<$ B $>$ no $</$ B $>$

$<$ A $>$ no $</ A>$

$<B>$ with a Erasmus grant .. Erasmus grant . $<$ overlap $/>$ you know . $</ B>$

$<$ A $><$ overlap $/>$ oh yeah okay okay yes $</ A>$

$<B>$ yes and I have been for three month $(\ldots)</ B>$

(SP19)

(33) $<$ A $>$ but is that your reason or it just doesn't attract you as a profession because there are two different reasons aren't they </A $>$

$<$ B $>$ last year (er) we could (er) there was a: .. psy $=(e h)<$ foreign $>$ une section

psychopédagogique $</$ foreign $></ B>$

$<$ A $>$ yeah $</ A>$

$<$ B $>$ you know and I took (er) I chose (eh) two: courses $(\ldots)</ B>$

(FR43)

This function was also recognized by Erman (2001: 1350-1351), who considers you know a social monitor in such cases, as well as by Fox Tree and Schrock (2002: 739-740) and Müller (2005: 181-183). In the present corpus this category is rather small, and only surfaces in the learner sub-corpora (Table 12). The French learners particularly use you know here to signal uncertainty about the form of their own message.

The independent-samples Kruskal-Wallis test was highly significant: $X^{2}(4, N=250)=$ 13.08, $p=.011$. The post-hoc tests indicate that a statistically significant difference only holds between LOCNEC and the French learner corpus, at $p<.05(\mathrm{H}=17.77)$. 
Table 12 Quantitative overview of the 'comprehension-securing' function

of you know

\begin{tabular}{lrrrr}
\hline & N & Rel. & Share & N int. \\
\hline LINDSEI-DU & 2 & 0.25 & 1.09 & 2 \\
LINDSEI-FR & 11 & 1.20 & 6.25 & 7 \\
LINDSEI-GE & 1 & 0.12 & 1.41 & 1 \\
LINDSEI-SP & 6 & 0.93 & 3.61 & 6 \\
\hline LOCNEC & 0 & 0.00 & 0.00 & 0 \\
\hline
\end{tabular}

\subsubsection{Transition to reported speech}

You know has the capacity to mark a transition to reported speech. It shares this function with other pragmatic markers, such as BE+like (e.g. I was like why did he do that?) and well. It would seem that you know occupies an intermediary position between these two quotative markers. On the one hand, it is similar to like, as it can be interpreted as marking that the upcoming stretch of reported speech should not be taken literally but is rather an approximation along the lines of what was actually said in the reported speech event. On the other hand, there is some ambiguity similar to that noted for well (cf. Müller, 2005: 114; Buysse, 2015) as to whether the marker belongs to the reported speech itself or not and consequently merges another one of its functions with this quotative use. For example, in (34) you know can be interpreted as belonging to the interviewee's father's speech, prefacing a proposition, whereas this double interpretation is less likely in (35).

(34) $<B>(. .$.$) at first I was like oh no I can't go to Australia you know I'm eighteen years$ old I can't do that . but then my dad said you know maybe it's a good idea if you . actually do: go to Australia $(\ldots)</ B>$

(DU27)

(35) $<B>$ (...) so I was teaching to supplement my income really . and then somebody said to me you know where are you gonna go in life $(.)<./ B>$ (NS22)

This function has been widely observed in prior research, e.g. by Schiffrin (1987: 282), Erman (2001: 1342), Fox Tree and Schrock (2002: 740), González (2004: 182-183), 
Müller (2005: 167-171) and Redeker (2006: 345). The quotative category is rather small in the learner sub-corpora (Table 13), with only slight differences between them, and is considerably more common in the native sub-corpus.

The independent-samples Kruskal-Wallis test was highly significant: $X^{2}(4, N=250)=$ $52.74, p=.000$. The post-hoc tests indicate that highly statistically significant differences hold between LOCNEC and all learner sub-corpora at $p<.001$ (for $\mathrm{DU} \mathrm{H}=46.78$, for FR $\mathrm{H}=46.95$, for $\mathrm{GE} H=54.76$, and for SP $\mathrm{H}=49.61$ ).

Table 13 Quantitative overview of the 'quotative' function of you know

\begin{tabular}{lrrrr}
\hline & N & Rel. & Share & N int. \\
\hline LINDSEI-DU & 7 & 0.88 & 3.83 & 4 \\
LINDSEI-FR & 7 & 0.77 & 3.98 & 4 \\
LINDSEI-GE & 1 & 0.12 & 1.41 & 1 \\
LINDSEI-SP & 5 & 0.77 & 3.01 & 3 \\
\hline LOCNEC & 36 & 2.86 & 6.28 & 23 \\
\hline
\end{tabular}

\subsubsection{Indicate a transition-relevance place}

You know has been observed to operate as a turn management device, both in turn-taking and turn-yielding (Östman, 1981; Holmes, 1986; Schiffrin, 1987; Erman, 2001; Fox Tree and Schrock, 2002). In interviews the selection of the speaker is largely directed by the interviewer, so you know does not occur turn-initially in the present corpus. There are instances where you know indicates a transition-relevance place, though. This function differs from the comprehension-securing function (see Section 3.2.7) in that the speaker is not voicing any uncertainty over what they have just said, which would require verifying whether co-participants have understood. Instead with the turn-yielding function of you know the speaker indicates that they want to abandon the topic, give co-participants the opportunity to take the floor while reserving their right to continue the turn themselves as well.

(36) $<B>$ yeah and $(e m)$. so we could see a few (er) repetitions of . that play </B> $<\mathrm{A}>(\mathrm{mhm})</ \mathrm{A}>$ 
$<B>$ and maybe . it was that's why I <laughs $>$ found it very good but . you know . $</ \mathrm{B}>$

$<A>$ you felt sympathetic with them or . with the actors $</ A>$

(DU16)

(37) $<$ B > yeah .. I mean there'd there'd been a drive by shooting .. erm where I was staying the week before $</ B>$

$<$ A $><$ laughs $></ A>$

$<B><$ laughs $>$ but I was so naive to it all $<$ /B $>$

$<\mathrm{A}>\mathrm{mhm}</ \mathrm{A}>$

$<B>$.. you know $</ B>$

$<$ A $>$ it's hard to imagine I think $</ A>$

$<\mathrm{B}>[$ yeah $</ \mathrm{B}>$

$<A>$ [ when you're not . there . $</ A>$

(NS17)

This function of you know is highly infrequent in the corpus as a whole (Table 14), which is probably due to the limited flexibility for turn management in an interview format. The independent-samples Kruskal-Wallis test was highly significant: $\mathrm{X}^{2}(4, N=250)=12.80$, $p=.012$. The post-hoc tests indicate that statistically significant differences only hold between LOCNEC and LINDSEI-GE $(\mathrm{H}=20.00)$ as well as LINDSEI-SP $(\mathrm{H}=17.36)$ at $p<.05$.

Table 14 Quantitative overview of the turn-yielding function of you know

\begin{tabular}{lrrrr}
\hline & N & Rel. & Share & N int. \\
\hline LINDSEI-DU & 3 & 0.38 & 1.62 & 3 \\
LINDSEI-FR & 4 & 0.44 & 2.27 & 4 \\
LINDSEI-GE & 0 & 0.00 & 0.00 & 0 \\
LINDSEI-SP & 2 & 0.31 & 1.20 & 1 \\
\hline LOCNEC & 9 & 0.72 & 1.57 & 8 \\
\hline
\end{tabular}

\section{Discussion}

In the present corpus you know appears to present itself as a polysemous pragmatic marker, i.e. as one and the same form that takes on different functions that share a common core (cf. 
Hansen 1998; Fischer 2006). You know pertains to the assumed or perceived knowledge status of a co-participant, closely related to its propositional origins as in Do you know where Annie is? or, more assertively, You know where Annie is. In its capacity as pragmatic marker you know marks the speaker's assumption that some form of common ground exists or can be established with a co-participant. This common ground may take the form of shared knowledge of a specific context or of the world at large. In its comprehension-securing function, for example, you know verifies whether the information contained in the prior proposition is familiar to the co-participant. When it elaborates a prior utterance in the form of a paraphrase, explanation or example, the speaker equally voices their uncertainty about the co-participant's understanding of what precedes but immediately also offers clarification, thereby ensuring a balanced knowledge base. In such instances you know at the same time has the effect of a politeness device: it prevents all parties from losing face, as the coparticipant is not pictured as ignorant nor can the speaker be accused of viewing the coparticipant as ignorant. A speaker may use you know following an utterance they presume is - or has the potential of becoming - a "consensual truth" (Schiffrin, 1987: 292). The marker then explicitly instructs a co-participant to retrieve information from either a mutual background or from their knowledge of the world so they can make the appropriate inferences in order for them to accept the proposition as a shared view. When indicating a transition-relevance place, you know does not refer back to a specific utterance from which inferences should be drawn, but the speaker rather sends the message that whatever they could add to the topic at hand should not be made explicit as the co-participant can already infer it from the prior co-text in general.

When the speaker cannot reasonably assume that the information contained in a proposition is known to a co-participant, you know serves as an appeal to the coparticipant's empathic capacity. In most cases a co-participant can, for example, not be expected to know stretches of reported speech allegedly quoted by the speaker. What you know does here, though, is signal that the co-participant should activate their knowledge of similar contexts as the one referred to so as to situate the reported speech in a proper framework of reference. In the same vein, in marking an approximate formulation with you know, the speaker indicates their awareness of the potential inadequacy of the upcoming proposition, instructing the co-participant to infer comparable situations to complete the picture. As an editing marker it takes this use to the extreme: co-participants are instructed to attempt to fill in possible gaps in the discourse. If a speaker introduces a new claim, 
background information or an event in a narrative, you know does not indicate the speaker's reliance on shared background knowledge but rather incites co-participants to consider the situation referred to as familiar or at least as one they can relate to. In highlighting a particular point in an utterance the speaker may mark the information it contains as given, and therefore part of the common ground.

It should be clear from this discussion that all of these functions are inherently, though not exclusively, oriented towards co-participants and are therefore essentially intersubjective. Although co-participants are rarely required to respond explicitly, in using you know speakers demonstrate awareness of the need to verify whether their interlocutors understand, share, or can relate to the message. You know is thus clearly an interpersonal marker, also in a context where the interlocutors are relative strangers and have no obvious desire to forge a "Camaraderie relation" (Östman, 1981: 19). The use of you know is not merely meant to check whether speaker and hearer are on the same wavelength, but just as much reflects a general desire among participants in a conversation to draw co-participants into a narrative, an argumentation or a topic, and to keep their attention by appealing to frameworks of reference that are familiar to them as well as to their empathic capacity towards the speaker.

Even though all functions incorporate the basic core of intersubjectivity, they do not necessarily do so to the same extent. Intersubjectivity is obviously most outspoken for those functions in which you know predominantly or solely appears in final position - viz. when it is an explicit invitation to make inferences, is comprehension-securing, or indicates a TRP since elements in the right periphery could be considered more explicitly interpersonal than markers occurring elsewhere in the clause (cf. Brinton, 1996). When placed clause-initially or -medially a textual function also comes to the fore. It is precisely the combination of an interpersonal and a textual element that distinguishes you know from other pragmatic markers that can occur in similar contexts. For example, we// too may fulfil a quotative function but merely marks the upcoming utterance as a direct speech quotation (cf. Aijmer, 2011: 244-245), whereas you know complements this with the interpersonal element of an appeal to a co-participant to situate the reported speech in a proper framework of reference.

All functions attested in the corpus are found in all sub-corpora (except for the very small comprehension-securing function, which is absent in the native sub-corpus). The quantitative discrepancy in the overall incidence of you know between the learner subcorpora on the one hand and the native sub-corpus on the other cannot be attributed to any 
one function but is rather apparent in at least all major functions of the marker (see Table 15). It would seem that, on the whole, even learners who are nearing the end of their formal learning process do not use a marker with predominantly interpersonal functions to a great extent, and that this is not dependent on their mother tongue background. It is of course difficult to find a hard and fast explanation for why someone does not make use of a linguistic item. Nonetheless, an interplay of various factors can be conceived of. First, a learner's primary aim in conversation may be to get a propositional message across, thereby pushing back any interpersonal aim they may have and for which a pragmatic marker of the type of you know would be well-suited. Second, formal education pays little attention to pragmatic markers (cf. Fung \& Carter, 2007; Romero Trillo, 2007), and textbooks have been noted to either ignore them or focus on a highly restricted set of markers, often with a narrow functional scope (cf. Müller, 2005; Lam, 2010). Learners may, as a consequence, not be familiar with how you know can be used effectively, in what contexts, etc. Third, learners who are familiar with it through exposure to English outside the classroom such as in television series or films may not be aware that their native peers use you know in the relatively formal register of an interview as well and not just in casual conversation among familiars. Finally, it cannot be ruled out that some learners are aware of negative attitudes towards interpersonal pragmatic markers such as you know and like, as have been reported by among others Fox Tree (2007) and Miscovic-Lucovic (2009). If such attitudes are, for example, propagated by language teachers (e.g. "don't use you know because it makes you seem unskillful"), learners may develop an avoidance strategy.

The role played by the learners' mother tongue is difficult to gauge. Negative L1 transfer can usually be detected when learners use a target language form either differently or much more frequently than native speakers. Neither is the case in the present corpus. Müller (2005) cautiously suggests that the German non-native speakers of English in her study may use you know less often as they "might suspect L1 interference" (2005: 251) with the German forms weißt du and (more colloquially) weißte. Similar glosses exist in Dutch (weet je) and French (tu sais) but not to my knowledge in Spanish (cf. also González, 2004). Moreover, none of these forms seem fully functionally equivalent to English you know (e.g. they do not perform an editing function), although relevant research is lacking to date. Müller's (2005) argument could also be turned around: if learners are already familiar with a similar form in their mother tongue, they will use you know in English (positive L1 transfer). 
In short, further contrastive research into which pragmatic markers are used in different languages (and how) should shed further light on this.

Although the relative frequencies are remarkably similar across the learner groups and no statistically significant differences appear to hold between them, one interesting tendency emerges. Indeed, the German learners have the lowest frequencies in almost all respects: the lowest number of interviewees (17) who use you know, with by far the smallest distribution range across the population, and the relative frequencies are well below those for the other learner groups. This tallies with Müller's (2005) observation that native speakers of German make infrequent use of you know.

Table 15 Overview of relative frequencies (per 10,000 words) and shares of each function within each subcorpus

\begin{tabular}{lcccccccccc}
\hline & \multicolumn{2}{c}{ LINDSEI-DU } & \multicolumn{2}{c}{ LINDSEI-FR } & \multicolumn{2}{c}{ LINDSEI-GE } & \multicolumn{2}{c}{ LINDSEI-SP } & \multicolumn{2}{c}{ LOCNEC } \\
& rel. & share & rel. & share & rel. & share & rel. & share & rel. & share \\
\hline PROP & $6.75^{*}$ & 29.19 & $4.92^{*}$ & 25.57 & $2.91^{*}$ & 35.21 & $6.17^{*}$ & 24.10 & 12.41 & 27.23 \\
EDIT & $5.78^{*}$ & 24.86 & $5.36^{*}$ & 27.84 & $1.86^{*}$ & 22.54 & $8.49^{\star}$ & 33.13 & 8.67 & 19.02 \\
HIGH & $3.64^{*}$ & 15.68 & $1.75^{*}$ & 9.09 & $1.28^{*}$ & 15.49 & $3.09^{+}$ & 12.05 & 6.53 & 14.31 \\
INF & $3.52^{*}$ & 15.14 & $1.42^{*}$ & 7.39 & $0.81^{*}$ & 9.86 & $2.01^{+}$ & 7.83 & 6.53 & 14.31 \\
ELAB & $1.26^{*}$ & 5.41 & $2.08^{*}$ & 10.80 & $0.81^{*}$ & 9.86 & $2.93^{*}$ & 11.45 & 5.97 & 13.09 \\
QUOTE & $0.88^{*}$ & 3.83 & $0.77^{*}$ & 3.98 & $0.12^{*}$ & 1.41 & $0.77^{*}$ & 3.01 & 2.86 & 6.28 \\
APPR & 0.75 & 3.24 & 0.88 & 4.55 & 0.35 & 4.23 & 0.46 & 1.81 & 1.03 & 2.27 \\
TRP & 0.38 & 1.62 & 0.44 & 2.27 & $0.00^{\star}$ & 0.00 & $0.31^{\star}$ & 1.20 & 0.72 & 1.57 \\
COMP & 0.25 & 1.09 & $1.20^{\star}$ & 6.25 & 0.12 & 1.41 & 0.93 & 3.61 & 0.00 & 0.00 \\
UNCL & $0.00^{+}$ & 0.00 & 0.44 & 2.27 & $0.00^{+}$ & 0.00 & 0.46 & 1.81 & 0.88 & 1.92 \\
\hline
\end{tabular}

Statistically significant differences between a learner sub-corpus and LOCNEC have been indicated as follows: ${ }^{\wedge} p<.05,{ }^{\dagger} p<.01,{ }^{*} p<.001$.

If we look at the relative shares of functions within each sub-corpus (Table 15), the function of you know marking an upcoming proposition as relevant to a co-participant ranks highly in all sub-corpora. Regardless of differences in absolute and relative frequencies, it takes a remarkably similar share in each sub-corpus, ranging from $24.1 \%$ in the Spanish and $25.57 \%$ in the French learner sub-corpora over $29.19 \%$ in the Dutch to $35.21 \%$ in the German learner sub-corpus. Only the French and Spanish learners use you know more often for editing purposes than to introduce a proposition. On the other hand, the editing 
function has across the board a higher share of tokens of you know in the learner than in the native data. This is also the category for which the learners (apart from the German group) most closely approximate the native frequency of you know. Even though it is also the second most popular function for the marker among the native participants, it stands to reason that the shares for this function within each learner group are still higher, since learners are likely to experience problems in looking for an appropriate lexical item to a greater extent than native speakers. This then increases the likelihood for you know to appear in an effort to overcome these problems.

\section{Conclusion}

A qualitative analysis of 1,167 tokens of the pragmatic marker you know has demonstrated that it is an essentially intersubjective marker, for native speakers and learners of English alike. Although the editing function of you know could be regarded as a "self-serving strategy" (House, 2009: 178) by which speakers "monitor their own progression in discourse" (House, 2009: 189), the marker still retains its appealing and inferential capacity towards coparticipants. On the whole, the learners who use you know have the greatest preference either for this editing function or, even more commonly, to signal co-participants that they can relate to the upcoming proposition because it fits in their shared framework of reference. This is exactly the same function that ranks highest in the native corpus. The differences between the native and learner sub-corpora appear to be more quantitative than qualitative: all functions attested for the native speakers also occurred in the learners' discourse, but the relative frequencies were consistently lower in the latter and considerably fewer learners used you know at all. The distribution ranges suggest that you know is a marker that some native and non-native speakers alike turn to time and again whether other, again native and non-native, speakers appear to shy away from it.

In spite of the relatively large size of the participant groups in the corpus, there are some limitations to the study. It should be borne in mind that, on the one hand, the learners were not individually tested for language proficiency levels which means that there is no guarantee that they form a fully homogeneous group within each sub-corpus, and on the other hand, that idiosyncratic preferences for pragmatic strategies will always exist both in native and non-native speech. The study also focused on a single text type, as a 
consequence of which certain functions may occur more or less frequently than if a different text type had been scrutinized. Then again, the speech conditions were similar for all participant groups, ensuring comparability between them. Finally, corpus research in the field of pragmatics inevitably relies on the researcher's interpretation of utterances. The resulting findings could be tested further in experimental settings and in attitudinal surveys to verify, for example, whether interactants indeed experience you know as a marker of common ground and an invitation to retrieve background information. This, however, clearly falls beyond the scope of the present study.

Two major avenues for further research on how learners of English use you know present themselves as particularly viable. First, the input side of learners' knowledge and skills can be focused on by investigating pragmatic aspects of teaching materials and classroom discourse as well as by mapping teachers' attitudes to pragmatic markers. Second, contrastive analyses between the learners' mother tongue and the target language can help gauge the extent of (positive or negative) L1 transfer in the learners' discourse.

\section{References}

Aijmer, Karin, 2011. Well I'm not sure / think... The use of wel/ by non-native speakers. International Journal of Corpus Linguistics 16 (2), 231-254.

Beeching, Kate, 2016. Pragmatic Markers in British English. Meaning in Social Interaction. Cambridge University Press, Cambridge.

Brinton, Laurel J., 1996. Pragmatic Markers in English. Grammaticalization and Discourse Functions. Mouton de Gruyter, Berlin/New York.

Buysse, L., 2015. 'Well it's not very ideal...' The pragmatic marker 'well' in learner English. Intercultural Pragmatics 12 (1), 59-89.

Erman, Britt, 2001. Pragmatic markers revisited with a focus on you know in adult and adolescent talk. Journal of Pragmatics 33 (9), 1337-1359.

Fischer, Kerstin, 2006. Towards an understanding of the spectrum of approaches to discourse particles: introduction to the volume. In: Fischer, K. (Ed.), Approaches to Discourse Particles. Elsevier, Amsterdam, pp. 1-20.

Fox Tree, Jean E., 2007. Folk notions of um and uh, you know, and like. Text \& Talk 27 (3), 297-314. 
Fox Tree, Jean E., Schrock, Joseph C., 2002. Basic meanings of you know and I mean. Journal of Pragmatics 34 (6), 727-747.

Fung, Loretta, Carter, Ronald, 2007. Discourse markers and spoken English: Native and learner use in pedagogic settings. Applied Linguistics 28 (3), 410-439.

Gilquin, Gaëtanelle, De Cock, Sylvie, Granger, Sylviane, 2010. Louvain International Database of Spoken English Interlanguage. Presses Universitaires de Louvain, Louvain-laNeuve.

González, Montserrat, 2004. Pragmatic Markers in Oral Narrative: The Case of English and Catalan. John Benjamins, Amsterdam/Philadelphia.

Hansen, Maj-Britt Mosegaard, 1998, The Function of Discourse Particles: A Study with Special Reference to Spoken Standard French. John Benjamins, Amsterdam.

Holmes, Janet, 1986. Functions of you know in women's and men's speech. Language in Society $15(1), 1-21$.

House, Juliane, 2009. Subjectivity in English as Lingua Franca discourse: The case of you know. Intercultural Pragmatics 6 (2), 171-193.

Jucker, Andreas H., Smith, Sara W., 1996. Explicit and implicit ways of enhancing common ground in conversations. Pragmatics 6 (1), 1-18.

Jucker, Andreas, Smith, Sara, 1998. And people just you know like 'wow': Discourse markers as negotiating strategies. In: Jucker, A. H., Ziv, Y (Eds.), Discourse Markers: Descriptions and Theory. John Benjamins, Amsterdam/Philadelphia, pp. 171-201. Lam, Phoenix W. Y., 2010. Discourse particles in corpus data and textbooks: The case of well. Applied Linguistics 31 (2), 260-281.

Miskovic-Lukovic, Mirjana, 2009. Is there a chance that I might kinda sort of take you out to dinner? The role of the pragmatic particles kind of and sort of in utterance interpretation. Journal of Pragmatics 41 (3), 602-625.

Müller, Simone, 2005. Discourse Markers in Native and Non-Native English Discourse. John Benjamins, Amsterdam/Philadelphia.

Östman, Jan-Ola, 1981. You know: A Discourse-Functional Approach. John Benjamins, Amsterdam/Philadelphia.

Redeker, Gisele, 2006. Discourse markers as attentional cues at discourse transitions. In: Fischer, K. (Ed.), Approaches to Discourse Particles. Elsevier, Amsterdam, pp. 339-358. Romero-Trillo, Jesús, 2002. The pragmatic fossilization of discourse markers in non-native speakers of English. Journal of Pragmatics 34 (6), 769-784. 
Romero-Trillo, Jesús, 2007. Adaptive management in discourse: The case of involvement discourse markers in Spanish conversations. Catalan Journal of Linguistics 6, 81-94.

Schiffrin, Deborah, 1987. Discourse Markers. Cambridge University Press, Cambridge.

Stubbe, Maria, Holmes, Janet, 1995. You know, eh and other 'exasperating expressions': An analysis of social and stylistic variation in the use of pragmatic devices in a sample of New Zealand English. Language \& Communication 15 (1), 63-88.

\section{Acknowledgements}

I would like to thank the two anonymous reviewers for their insightful comments.

\section{Appendix: Transcription conventions}

\begin{tabular}{|c|c|}
\hline$<A>$ & Interviewer turn starts \\
\hline$<\mathrm{B}>$ & Interviewee turn starts \\
\hline$</ A>$ & Interviewer turn ends \\
\hline$</ B>$ & Interviewee turn ends \\
\hline$\ldots$ & Empty pause: . (short), .. (medium), ... (long) \\
\hline [ ] & Phonetic annotations (e.g. the[i:], a[ei]) \\
\hline : & Vowel lengthening (e.g. so:) \\
\hline$=$ & Truncation \\
\hline$<\mathrm{X}>$ & Unintelligible word \\
\hline$<$ overlap > & Overlapping speech \\
\hline$<$ foreign $>$ & Foreign words \\
\hline$<$ coughs $>$ & Non-verbal sounds and contextual comments are specified in angle \\
\hline
\end{tabular}

